\title{
THE BEST STRATEGY FOR FORMING CHILDCARE FROM AN EARLY AGE
}

\author{
Mochamad Soelton, Harefan Arief, Yanto Ramli, Margono Setiawan, Fatchur Rohman, and Mugiono \\ Universitas Mercu Buana Jakarta, Indonesia \\ Universitas Brawijaya, Indonesia.
}

\begin{abstract}
Families who live in rural areas prioritize the fulfillment of economic needs rather than patterns of care for their children. Parenting is an effort made by parents in preparing children to have the competencies needed to be ready to live in the community. So that parents have an important role in the lives of children. Brooks identified four parental roles specifically in influencing a child's development, namely providing a protective environment, providing experiences that lead to the development of maximum potential, being an advisor in a larger community, becoming an irreplaceable force in a child's life
\end{abstract}

Keywords: Parenting, Children's, Early Age

\section{INTRODUCTION}

Lately, many cases of violence against children have emerged, both aired through television and print media. There are two types of violence that are prominent, namely physical and economic violence. But basically these two types are interrelated with each other, while also being a causal relationship. Physical violence that is often found such as beatings on children, other torture by burning children and so on. This certainly invites deep concern. The cause is sometimes trivial, when parents are annoyed because the child continues to whine for allowance, then from there the parent then becomes furious which results in physical abuse on the child. If traced further, a prolonged economic crisis will also cause this condition to occur. Not to mention coupled with policies regarding the increase in fuel which in one year there have been 2 (two) times the increase. Further implications, the people are increasingly screaming, especially from the lower middle class.

Moreover, for the people whose lives rely solely on income as a result of the work of the child such as busking, shining shoes. Even today many young children who are still very early in age have roamed the crossroads precisely near the traffic light, they raised their hands waiting for a few rupiahs from road users. While the parent is sometimes on the sidewalk, the street waits until the child gets the money he wants.

The child only knows that he must always obey what his parents ordered. Without complaint, the child continues to beg without knowing that he actually has the right to enjoy his childhood. His childhood was seized by the cruel struggle to face life in the shadow of his parents. The world of children who are supposed to be filled with play, is instead replaced by the heat in the middle of the highway. This condition can be found at intersection and its surroundings. Every day the sight of children busking alternating with parents and adults.

In developing children to become quality human resources, proper preparation and treatment of children is needed in accordance with the child's condition. As humans, every child has individual characteristics that are different from one another. In addition, every child born in this world has the right to live and develop as much as possible in accordance with the conditions they have. To be able to provide development opportunities for every child requires proper parenting from their parents, this is because children are the responsibility of their parents physically, psychologically and socially (Nuryoto, 1998).

\section{LITERATURE REVIEW}

A 2013 World Bank impact evaluation found positive correlations between higher levels of parenting knowledge and abilities and better outcomes for children, beyond parents' income and education: Parents with higher levels of warmth and consistency, and lower levels of hostility, generally had children with fewer behavior problems, better health, increased emotional maturity, higher communication skills, and strong cognitive development (Hasan, Hyson, and Chang 2013).

Achieving of Parenting to strengthen parents' and other caregivers' knowledge about how their actions affect child development and give them skills to help their child's health development and school readiness. The first education obtained must be from family. Therefore the participation of parents is very central. The role of family is to make children have a high quality and grows as their ages. According to (Brooks and Markman, 2005), parents influence children in several ways: 
1. Nurturance - a ways to express love, affection, and attention, to be warm and sensitive to children's behavior changes and negative attitudes.

2. Discipline - response to children's behavior that is considered appropriate by parents or inappropriate based on the child's gender, age, parental beliefs, parenting, and culture.

3. Teaching - communicating information or skills to children through activities, discussions, questions, modeling, and opportunities for practice and experience.

4. Language - communication between parent and child is conveyed

5. knowledge, emotions, values, and culture and measured by the number of words, listen, long sentences, questions asked, descriptions of children's speeches, the program being discussed, storytelling, and the presence and style of reading activities.

6. Monitoring - supervision of the safety and welfare of children, like periodically checking a child who is playing alone, observing what a child sees during screen time, and knows who the child is with and what the child did when not at home.

7. Management - schedule events, carry out planned events, whether that means going to a playground or getting an immunization injection, and watching household rhythms, such as bedtime and mealtime routines, everything which often requires a lot of time and energy to care for children.

The family as a cell only acts with love and respect and dominates understanding, affection, child sacrifice and parenting. (Emerllahu, Dali, 2001) So, in this way building a family environment, where we live, laugh, play, and develop children. (Claudia \& Eberhard Muhlan. 2008). The Parents take an important attitude, when it comes to the development and education of their children as a whole, like parents themselves are people who care for children as a whole both physically and intellectually development, to the extent that they are independent and ready to face the challenges of the communities where they live.

When parents involve themselves in the education process of their children, usually the results can be qualify as positive and uplifting. In this case, they are usually connected and acted under themselves the attitudes of parents, transmitted through demonstrations of their mutual confidentiality regarding children's abilities and their overall learning capacities that lead them to success in learning, education as a complex process.

On the other hand, parenting education programs have been repeatedly proven effective for parents of children in developed and developing countries when delivered well. They can actually be most effective with those families who are most in need, including in low and middle income countries (Eshel et al. 2006; Evans 2006).

Hornby (2005) states model of theory Parental involvement is a combination of and adaptation of previous models (such as Bastiani, 1989; Kroth, 1985; Lombana, 1983; Wolfendale, 1992, in Hornby,(2010) as well as a collection of responses given by several groups of parents and teachers. Model of parent involvement adaptation from Hornby (2010) consisted of two pyramids which represented level of parental needs (parental needs) and level of strength (parental contributions) which owned by parents or contributions that can be given by parents.

\section{METHOD}

This training uses the experiential learning methods with the interactive communication techniques, the dialogue, the discussion, the role play / games, where the participants are introduced to the concept, then directly involved feeling, experiencing, discussing the process and the results of this training to successful training in raising parenting in a family.

The training was held in collaboration with the Faculty of Economics and Business, Mercu Buana University (UMB) with Amanah kindergarten Meruya Selatan. UMB helped provide the speakers, the seminar handouts, the pre-post test, the evaluation, and the snack materials, while the Amanah kindergarten Meruya Selatan helped to condition the participants, provided a place (room), and equipment / training equipment. The training participants were 30 participants in this activity. Participants in child parenting training activities in the family consist of:

1. Parents of the Amanah kindergarten Meruya Selatan

2. Teacher of Amanah kindergarten Meruya Selatan

3. The community around the Amanah Kindergarten Meruya Selatan 


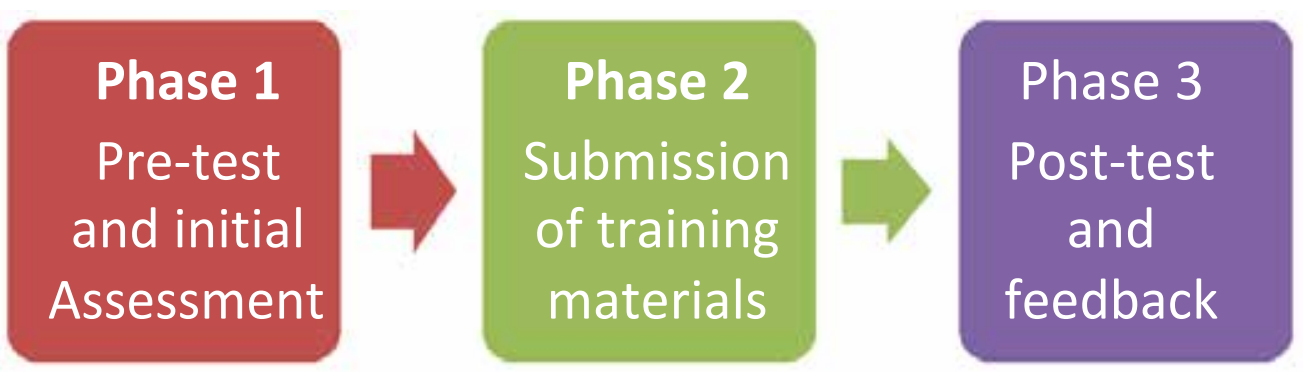

\section{Phase 1: Pre-test and initial assessment of participants}

After the opening ceremonial event and before the material was delivered, the participants were asked to fill out the questionnaire as a pre-test. The initial assessment of the participants was carried out by filling out the training registration form.

\section{Phase 2: Submission of training materials by instructors}

Training material consist of a presentation, brainstorming, brainstorming, and dialogue . The selection of this method is carried out with the aim of achieving the desired target of successful training in raising parenting in a family.

\section{Phase 3: Post-test and feedback}

Before closing, the participants were asked to fill in the post-test, and evaluate the event, messages and the impressions from the participants as feedback.

\section{RESULTS AND DISCUSSION}

Parenting and parenting are two different things that are very important for parents to know. Care is something that includes the process of looking after and caring for children such as feeding, maintaining their health and protecting your child from threats and dangers that can take his life. There is also socialization or what we know by teaching behavior that is in accordance with applicable rules in the community, namely education about how children can interact with their environment in the community and finally communication. Meanwhile, different from parenting which means it is a style or way of parenting that is done by each parent and applied consistently to his baby. This parenting certainly has certain goals and objectives which are not surprising if between one parent and another parent has different parenting patterns.

It can be concluded that parenting is an attempt by parents in preparing children to have the competencies needed to be ready to live in the community. So that parents have an important role in the lives of children. Brooks identified four parental roles, especially in influencing child development, namely providing a protective environment, providing experiences that lead to the development of maximum potential, being an advisor in a larger community, becoming an irreplaceable force in a child's life.

\section{CONCLUSION}

Based on the discussion carried out in the previous chapters, the following conclusions can be made:

1. Some of the efforts made in training in parenting management in kindergarten Aminah in order to provide a good output in the context of parenting efficiency and effectiveness.

2. Learning through training is expected to contribute to increasing knowledge in terms of parenting, especially parenting .

Suggestion

Based on the evaluation process carried out in this training, several constructive suggestions were carried out as follows:

1. The participants must often train and practice in encouraging children to become more accustomed and reliable in improving patterns and quality of life .

2. Creating better conditions for caring for children to grow into a better person. 


\section{REFERENCES}

Brooks-Gunn, J., and L. B. Markman. 2005. "The Contribution of Parenting to Ethnic and Racial Gaps in School Readiness." The Future of Children 15 (1): 139-68.

Claudia \& Eberhard Muhlan (2008) Udhezues i madh I familjes, Vellimi II Tirane, pp.12

Central PKK Activator Team. 1995. Parenting Children in the Family: Guidelines for Parents, Jakarta

http://organ.org/ke Luck-benefits-applements-pola-hidup-sehat-ilmu .

Emerllahu, Dali, (2001), Edukata estetike, Prishtine, pp.284

Eshel, N., B. Daelmans, M. C. de Mello, and J. Martines. 2006. "Responsive Parenting: Interventions and Outcomes." Bulletin of the World Health Organization 84 (12): 992-99.

Evans, J. 2006. Parenting Programmes: An Important ECD Intervention Strategy. Paris: UNESCO.

Hasan, A., M. Hyson, and M. Chang, eds. 2013. Early Childhood Education and Development in Poor Villages of Indonesia: Strong Foundations, Later Success. Washington, DC: World Bank.

Healthy Lifestyle. Available on http;//id.shvoong.com/medicine-and-health/1747401-akukan-polaliving-sehat/.

Honby, G., \& Witte, C. (2010). Parent involvement in inclusive primary schools in new zealand: Implications for improving practices and for teacher education. International Journal of Whole Schooling. Vol. 6, No. 1 (pg. 27- 38). 